\title{
Opportunities for Transportation Departments to Leverage Construction UAS Data
}

\author{
Bryan Hubbard $^{1}$ and Sarah Hubbard ${ }^{2}$
}

1 Purdue University, West Lafayette, USA, bhubbard@purdue.edu

2 Purdue University, West Lafayette, USA, sarahh@purdue.edu

\begin{abstract}
Unmanned Aerial Systems (UASs) are being used on infrastructure construction sites by contractors for many different applications and generate valuable data that could be potentially leveraged for Department of Transportation (DOT) applications. Representative UAS construction applications include construction progress monitoring, safety surveillance, quality assurance, documentation of work zone conditions following an incident, quantity measurement, and communication with stakeholders. The UAS data typically consists of high definition pictures and video from a standard commercial drone. Many of these constructor UAS applications directly relate to activities that are also important for DOTs such as monitoring construction activities, quality assurance, managing the safety of the work zone and construction project. This paper reviews the potential UAS applications that benefit both contractors and DOTs and presents results of a survey regarding common UAS applications.
\end{abstract}

(C) 2020 The Authors. Published by Budapest University of Technology and Economics \& Diamond Congress Ltd Peer-review under responsibility of the Scientific Committee of the Creative Construction Conference 2020.

Keywords: construction, Unmanned Aerial Systems (UAS), drone, Departments of Transportation (DOT)

\section{Introduction}

The construction industry utilizes UAS technology for numerous applications [1,2] and is at the forefront of expanding commercial UAS use in the private sector [3]. Data generated by these contractor led activities supports a number of DOT information requirements. The UAS applications discussed generally reflect a consumer grade UAS equipped with a high definition camera, and in some cases GPS and software processing to provide a georeferenced image. This reflects the kind of UAS commonly owned and operated by a construction firm. There are numerous new technologies being employed and developed for more sophisticated kinds of inspection, including LiDAR and FLIR (e.g., thermal, night vision and infrared) technology. These technologies provide even more detail of the structure and may be able to identify cracks, deformations, and delamination in structures [4]. While these technologies are starting to be used on infrastructure, the major focus of this paper is to identify how UAS images and videos captured during the construction process can be utilized by DOTs.

\section{UAS applications for road and bridge construction}

A literature review of UAS applications for road and bridge construction was undertaken to identify some of the most common applications based on commercial, off the shelf UAS equipment with imagery capabilities. The identified applications were used as the basis for a survey of road and bridge contractors and consultants. The construction applications identified are reviewed in the context of how a DOT could utilize the data to help achieve complementary objectives. For example, if a construction firm is utilizing UAS for progress photos of their job site, this imagery be useful for inventory analysis of DOT assets in the area such as signs, lighting, guardrails and drainage systems. The UAS applications for road and bridge 
construction are listed in Table 1. This section provides a summary of each application and identifies related potential opportunities for DOT opportunities.

Table 3. UAS Applications for Road and Bridge Construction Projects

\begin{tabular}{|l|}
\hline Monitor construction progress and/or site inspection \\
\hline Evaluate work zone to ensure safety of motorists and workers \\
\hline Document work zone after incident or accident \\
\hline Create imagery and 3D models for construction documentation and as-built information \\
\hline Estimate stockpile and excavation quantity \\
\hline Perform material tracking \\
\hline Support construction site logistics planning \\
\hline Support surveying operations \\
\hline Support communications, marketing, public information and public relations \\
\hline
\end{tabular}

\subsection{Monitor construction progress and/or site inspection}

Construction Application. An early application of UAS in the construction industry was to provide documentation of the progress on a construction site. Barfuss et al.[5] reported the Utah DOT used imagery from a UAS on a parkway project to observe the construction progress, cut and fill regions (no measurements), and record the phases of construction. A survey by Irizarry [6] identified monitoring construction project progress was one of the most useful tasks for UAS. Generating weekly aerial maps of the construction site can reduce the time spent by construction personnel having to walk the site and provide a visual record of the project [7].

DOT Opportunity. These high definition images provide the constructor with information about construction progress, and can also be used by the DOT to monitor the progress of the construction project and serve as a record of work completed. The aerial imagery from UAS also provides a way to inspect construction activities in areas that are difficult to get to and/or are potentially unsafe [6]. For example, temporary erosion control and sediment control can be monitored via UAS to ensure effectiveness $[8,9,10]$.

\subsection{Evaluate work zone to ensure safety of motorists and workers}

Construction Application. Evaluating the safety of a construction site through UAS imagery has been noted by numerous studies as an effective way to help improve worker safety on the worksite $[7,6]$. UAS images allow a safety manager to review large portions of the construction site quickly and safely and effectively evaluate the work zone to ensure workers are safe from the travelling public. The contractor can also use the images to ensure the work zone is accurately set-up, which ensures motorist safety and reduces liability. The resulting images can be used to communicate potential issues related to the work zone set-up.

DOT Opportunity. Worker safety is a concern for all stakeholders on a construction project. An accident on a construction site or in a work zone can cause many issues for all stakeholders and the project. In addition to the direct impacts of injuries and property damage, there are impacts due to lost time, project delays, reduced worker productivity, and administrative time for reporting and investigation. DOT benefits from new technologies that help support worker safety and from timely information on the work zone configuration. Drones provide imagery that can be used to identify adjustments that need to be made to correct a potentially dangerous work zone configuration and/or to ensure better traffic flow; as well as to document the improvements. This opportunity has been well established, and we documented a decade ago by [11] in an early feasibility study using drones to monitor work zones with drones.

\subsection{Document work zone after incident or accident}

Construction Application. Mapping crash scenes with UAS has been increasingly used by law enforcement at both the state and local level. Using UAS to document the crash scene (or site of the incident or accident) is faster than conventional methods, and allows the accident to be cleared quickly, which helps prevent secondary accidents [12]. While most of the focus has been on law enforcement requirements related to this function, contractors and DOTs also may benefit from the data obtained by a UAS at the crash scene $[13,14]$. Benefits include accurate documentation of the crash scene which is useful for insurance claims, 
criminal investigations, assessment of work zone configuration, review of traffic operations, and infrastructure condition such as the resulting damage to guardrail or bridge components [12]. Contractors may become involved in litigation related to the work zone incident or accident and UAS information may be helpful to provide an accurate representation of the construction site at the time.

DOT Opportunity: The data from a crash scene is useful for the construction contractor, and also may be useful for DOTs to improve work zone safety. The images and video may be used to evaluate why the incident occurred, and provide information to improve work zone design as well as train DOT employees in work zone design and set-up. Imagery of a crash scene or incident scene support future road safety improvements and can also support activities during litigation for all stakeholders, including DOTs. As noted by Rogers [15], video is often helpful in a legal setting to describe the incident. UAS imagery provides a much more robust context for incident or accident conditions, as compared to traditional accident reports.

\subsection{Create imagery and 3D models for construction documentation and as-built information}

Construction Application. An accurate 3D model representation of an infrastructure construction project once it is completed provides information for future repair, reconstruction and inspection. 3D models of the constructed facility can also be compared to the original design to assure construction accuracy [8]. These 3D models are based on data collected with UAS and photogrammetry software processing programs and may replace or be used as a backup to traditional drawings and specifications.

DOT Opportunity. There are numerous DOT benefits from 3D models that extend beyond the construction phase. The georeferenced images can serve as supplemental as-built information and provide a record of infrastructure condition. Cataloging images over a period of time provides DOTs with information that may be useful for warranty issues, for illustrating best practices, and for the provision of historic information that may be useful to improve future construction and maintenance practices for road and bridge systems.

\subsection{Estimate stockpile and excavation quantity}

Construction Application. The management of stockpiled material such as aggregate, and soil is important in the construction process to keep the project on schedule, and support material management, accounting and billing. Similarly, documentation of excavation and material movement during construction provides information regarding construction progress and is important for project documentation and payments. The volume of material and the excavation of material can be determined using UAS imagery and processing with photogrammetry software that generates a 3D model from 2D photos [16]. Accuracies are within approximately $+/-3 \%[16,17]$. If more accurate measurements are needed, more sophisticated systems can be used (e.g., higher resolution cameras with more sophisticated use of base stations for calibration and/or LiDAR).

DOT Opportunity. Accurate information about current material quantities volumes and current status of excavation and earth moving are important for the construction contractor and also support DOT progress assessment, as well as payment and accounting. As noted by McGuire et al., [13] "Close inventory inspection of stockpiles ensures that the supplier provides the correct amount, avoids stock-outs of material, and proper moisture amounts for road construction."

\subsection{Perform material tracking}

Construction Application. The ability to quickly locate required materials on a construction site is important for inventory management and job site productivity. Inventory management may utilize material identification using photographs, barcodes, or Radio Frequency Identification (RFID) technology $[18,19]$. Commercial systems manage inventory with material tracking that may utilize UAS or vehicle based systems. Material management and tracking supports the contractor by providing timely and accurate information regarding materials that are currently in the inventory and ready for placement, as well as materials that are expected but have not yet arrived on the job site. Utilizing advanced technologies such as UAS for material tracking also reduces loss from theft and supports site security measures [20]. 
DOT Opportunity. Improved material management and inventory control benefits DOTs by supporting onsite efficiency, reducing costs and reducing delays, resulting in shorter construction times. The imagery provides a good record of inventory in case there are questions or disputes during and after construction. DOTs may also find it useful to use this kind of system to track materials for maintenance and operations at the district level (e.g., salt, sand and gravel), ensuring that the appropriate material is available when needed, and ensuring that the quantity delivered is timed and billed appropriately.

\subsection{Support construction site logistics planning}

Construction Application. UAS can support job site logistics and logistics planning on for construction [6]. During the pre-construction planning phase, UAS can provide detailed site information to facilitate a detailed logistics plan that is tailored to the job site, including the location of material laydown, equipment location, construction site access, construction office location and parking. During the construction process, aerial images can provide information to support evaluation of material flow and worker productivity, as well as identify potential construction issues [18]. All these logistic related activities support a more efficient and safer worksite, which benefits both the contractor and the DOT.

DOT Opportunity. The imagery provided in the preconstruction and mobilization phase of a construction project will also support DOT activities, such as examination and documentation of existing conditions, inspection and confirmation of the traffic control plan, and locations and effectiveness of environmental controls such as silt fences [13]. The imagery can also be used to identify potential assets (e.g. drainage structures, traffic signs, and guardrails) that may be affected by construction; these assets may need to be moved, modified, and/or protected during the construction project and the UAS imagery can help identify as well as provide a robust context prior to construction mobilization.

\subsection{Support surveying activities}

Construction Application. The capability of UAS to produce low cost survey maps is improving and has been aided by technology such as Global Navigation Satellite System (GNSS) Real-Time Kinematics (RTK), which enhances the precision of position data [21]. While surveying may still require high-accuracy data that can be provided by more traditional survey techniques, there are numerous surveying functions, such as progress monitoring, that may use lower accuracy photogrammetry methods that leverage UAS mounted cameras. Some advantages of lower accuracy photogrammetry UAS methods include lower cost and the ability to collect data in remote or hard to access locations [22]. The reduction of survey crews on-site during construction operations reduces the exposure of survey crews to construction hazards and improves construction site safety [22].

DOT Opportunity. Inadequate progress monitoring may contribute to poor performance in transportation construction [22]. This can be addressed by enhanced monitoring, including the collection of UAS data to document work in-progress and work completed; this documentation also supports payments and payment schedules. Work progress can also be important when communicating with the public regarding construction schedules, closures, and work zone changes, as discussed in the next section.

\subsection{Support communications, marketing, public information and Public Relations}

Construction Application. UAS photos and video can be shared with internal and external stakeholders (Dronedeploy, 2018) to support communications, marketing, and public relations. UAS aerial imagery provides the construction team with visual data that is easy to interpret. Construction contractors share UAS imagery with numerous stakeholders including current and potential clients, as well as subcontractors.

DOT Opportunity. DOTs can also use UAS photos and video to support communications, public information and public relations. UAS photos and video can be posted on social media and DOT websites, and shared with the media. UAS imagery shared with the public may be useful to provide an overview of the project and project progress [7]. Imagery of the construction site also supports information about road detours and work zones, which may increase motorist safety. Some DOT divisions and districts have already used UAS images and videos for public information and public relations. 


\section{Results of survey of construction professionals}

An online survey of construction professionals was used to provide a better understanding of how UAS are being used on road and bridge construction projects. All responses were anonymous. The survey was distributed using a DOT construction listserv, which includes construction professionals who work for a DOT, as well as constructors and consultants in the private sector who do construction work under contract with a DOT. An objective of the survey was to identify how UAS are currently being used by contractors. Table 2 provides a ranked list of the applications currently performed by contractors from the survey. The most common application for construction projects is imagery for communications and marketing. Other popular application include estimating stockpile quantity (ranked 2nd) and imagery for as-built information and general construction documentation (ranked 3rd).

Table 2. Survey of UAS Applications

\begin{tabular}{|c|l|}
\hline Rank & Application (number of respondents using this application) \\
\hline 1 & Use imagery for communications and marketing (58) \\
\hline 2 & Estimate stockpile quantity (39) \\
\hline 3 & Create imagery and 3D models to provide as-built information and construction documentation (38) \\
\hline 4 & Monitor construction progress and/or site inspection (for example, silt fences) (37) \\
\hline 5 & Support surveying operations (37) \\
\hline 6 & Estimate excavation quantity (33) \\
\hline 7 & Support construction site logistics planning (23) \\
\hline 8 & Evaluate safety of construction site for workers (15) \\
\hline 9 & Perform material tracking (15) \\
\hline 10 & Document work zone after an incident or accident (10) \\
\hline 11 & Evaluate safety of work zone for motorists (8) \\
\hline 12 & Use for security monitoring (4) \\
\hline
\end{tabular}

Based on the survey results, UAS are widely used in construction and are using UAS imagery for communications and marketing, as well as more specialized applications such as 3D models to estimate quantities and provide as-built information. As technology advances, the use of this UAS data for payments and to confirm milestones will become more prevalent.

Responses to survey questions illustrate that many contractors have provided clients with UAS data on past projects and would be willing to provide clients data in the future. Considering past projects, $60 \%$ have provided clients with UAS data when requested (44\%) or if specified in the contract (16\%); $19 \%$ have provided clients with all UAS data during the project. About a fifth (21\%) indicated that they never provide UAS data to their client on past projects.

Concerning contractors and consultants willingness to provide UAS data in the future, the majority (57\%) indicated that they would provide the data if it is required in the contract. A large percentage (40\%) indicated they would provide the data if they are collecting the data anyway. Only 3\% indicated they would not be willing to provide data. Keep in mind that some contractors may not use UAS, and depending on their area of expertise, it may be uncommon to utilize UAS. In the comments to this question, some respondents expressed concerns about liability issues. There were also concerns regarding the contractor's burden and risk if UAS data is included as a contract deliverables.

Based on the survey results, UAS is widely used in construction, and there is interest in an expanded use in the future. The majority of constructors have their own equipment and are using UAS imagery for communications and marketing, as well as more specialized applications such as 3D models to estimate quantities and provide as-built information. As technology advances, the use of this UAS data for payments and to confirm milestones will become more prevalent. 
Providing a contractual mechanism for DOTs to obtain UAS images and video captured by contractors during construction is one way to quickly integrate UAS data without requiring a DOT to own or operate UAS. Many construction firms already collect this data, and it can potentially be provided to a DOT with minimal additional effort. It is important that the data requirements be clearly defined, and that adequate consideration is given to minimizing the contractor burden and risk, since standards and procedures are still being developed.

Another important consideration is development of a data management framework to ensure that the UAS data collected can be accessed and leveraged to support all DOT activities, as needed. For full benefit, UAS data provided to DOTs by contractors will need to be in a consistent format and stored so it is readily accessible for the many potential applications and users. FHWA has recognized that a standard format for data is a key issue, and hopefully a national standard will be forthcoming; even with a standard, there will still be a need for DOT to identify their own database requirements. Development of a robust database that leverages GIS capabilities will ensure that all UAS data can be leveraged and used to its full potential.

\section{Conclusion}

UAS are being used on construction sites by contractors for many different applications, and constructors are generating valuable data that could be potentially leveraged for DOT applications. UAS construction applications include construction progress monitoring, safety surveillance, quality assurance, documentation of work zone conditions following an incident, quantity measurement, and communication with stakeholders. The UAS data could be identified as a deliverable item in DOT construction contracts, and may include high definition pictures and video from a standard commercial UAS, as well as data such as earthwork quantities moved, or stockpile quantities associated with materials contracts. Many constructor UAS applications directly relate to activities that are important for DOT, such as monitoring construction activities, quality assurance, and managing the safety of the work zone and construction project. In addition to the construction applications that directly overlap with a DOT's mission, data from construction sites could also be utilized for other DOT applications beyond the construction phase. These applications may include roadside asset inventory (including signs and culverts), as built documentation, classification of plant species in the right-of-way, and video and images that can be used for communication with the public. The findings include the results of a survey of constructors, which indicates general willingness of constructors to provide UAS video and data as a contract deliverable.

\section{Acknowledgements}

The authors would like to acknowledge and thank the many people and organizations who provided information and supported this project, including Andy Fitzgerald, Barry Partridge and Tim Wells of the Indiana Department of Transportation This research was funding through the Indiana Joint Transportation Research Program.

\section{References}

[1] Irizarry, J., Kim, S., Johnson, E., \& Lee, K. (2017). Potential unmanned aircraft systems based operations within a Department of Transportation: Findings from a focus group study. In Proc., Int. Conf. Associated Schools of Construction (ASC) (pp. 669-679).

[2] Li, Y., \& Liu, C. (2019). Applications of multirotor drone technologies in construction management. International Journal of Construction Management, 19(5), 401-412. https://doi.org/10.1080/15623599.2018.1452101

[3] Hensel Phelps (2019, June 6). FAA Grants Hensel Phelps Approval for Drone Operations Over People. Retrieved from https://www.henselphelps.com/faa-grants-hensel-phelps-approval-drone-operationspeople/?fbclid=IwAR04PtD0Uip7fuA3deHsJ7KDkMgCYb8f5Sm0JhO5V813ISfMKMNM_yXHp08

[4] Seo, J., Duque, L., \& Wacker, J. (2018). Drone-enabled bridge inspection methodology and application. Automation in Construction, 94, 112-126. https://doi.org/10.1016/j.autcon.2018.06.006

[5] Barfuss, S., Jensen, A., \& Clemens, S. (2012). Evaluation and development of unmanned aircraft (UAV) for UDOT needs(No. UT12.08). Utah. Dept. of Transportation. Research Division.

[6] Irizarry, J., \& Costa, D. B. (2016). Exploratory study of potential applications of unmanned aerial systems for construction management tasks. Journal of Management in Engineering, 32(3), 05016001. https://doi.org/10.1061/(asce)me.1943-5479.0000422

[7] Drone Deploy (2018). Drones for Construction Project Management. An Introduction to Drones for Construction Project Management. Retrieved from http://www.rpas.co.za/attachments/drones_in_construction_management_F.pdf

[8] Irizarry, J., \& Johnson, E. N. (2014). Feasibility study to determine the economic and operational benefits of utilizing unmanned aerial vehicles (UAVs). Georgia Institute of Technology.

[9] Brooks, C., Dobson, R. J., Banach, D., Dean, D., Oommen, T., Wolf, R., \& Hart, B. (2015). Evaluating the use of unmanned aerial vehicles for transportation purposes. Michigan Tech Research Institute, and Michigan Technological University, 7. 
Proceedings of the Creative Construction e-Conference (2020) 013

Available online at e-2020.creative-construction-conference.com/proceedings/

[10] FHWA (2019). Unmanned Aerial Systems (UAS). Retrieved from https://www.fhwa.dot.gov/innovation/everydaycounts/edc 5/uas.cfm

[11] Gu, Y., Martinelli, D., Napolitano, M., \& Seanor, B. (2011). Evaluation of Remote Sensing Aerial Systems in Existing Transportation Practices, Phase II (No. WVU-2009-01). West Virginia. Dept. of Transportation.

[12] Bullock, J. L., Hainje, R., Habib, A., Horton, D., \& Bullock, D. M. (2019). Public Safety Implementation of Unmanned Aerial Systems for Photogrammetric Mapping of Crash Scenes. Transportation Research Record, 0361198119850804. https://doi.org/10.1177/0361198119850804

[13] McGuire, M., Rys, M. J., \& Rys, A. (2016). A study of how unmanned aircraft systems can support the Kansas Department of Transportation's efforts to improve efficiency, safety, and cost reduction (No. K-TRAN: KSU-15-3). Kansas. Dept. of Transportation. Bureau of Research.

[14] Yamanouchi, K. (2013, June 6). Tech to study use of drones for monitoring highway traffic. The Atlanta Journal-Constitution. Retrieved from https://www.ajc.com/business/tech-study-use-drones-for-monitoring-highway-traffic/Nb8t7qLOSKFIDRLIsnfQ2M/

[15] Rogers, P. (2019, July 10). FHWA Unmanned Aerial System Tech Brief Development and Every Day Counts Round 5 Support [Webinar]. Retrieved from https://intrans.iastate.edu/research/in-progress/fhwa-unmanned-aerial-system-tech-brief-development-andevery-day-counts-round-5-support/

[16] Arango, C., \& Morales, C. A. (2015). Comparison between multicopter UAV and total station for estimating stockpile volumes. The International Archives of Photogrammetry, Remote Sensing and Spatial Information Sciences, 40(1), 131. https://doi.org/10.5194/isprsarchives-xl-1-w4-131-2015

[17] Raeva, P. L., Filipova, S. L., \& Filipov, D. G. (2016). Volume Computation of a Stockpile - A study Case Comparing GPS and UAV Measurements in an Open Pit Quarry. International Archives of the Photogrammetry, Remote Sensing \& Spatial Information Sciences, 41. https://doi.org/10.5194/isprs-archives-xli-b1-999-2016

[18] Tatum, M. C., \& Liu, J. (2017). Unmanned aircraft system applications in construction. Procedia Engineering, 196, 167-175. https://doi.org/10.1016/j.proeng.2017.07.187

[19] Hubbard, B., Wang, H., et al. (2015, April), Feasibility Study of UAV use for RFID Material Tracking on Construction Sites", Associated Schools of Construction Annual International Conference, College Station, TX.

[20] Wang, H., Hubbard, B \& Hubbard, S. (2014, May), RFID Applied to Supply Chain Logistics in Disaster Recovery, 10th International Conference of the International Institute for Infrastructure Resilience and Reconstruction (I3R2), West Lafayette, IN. https://doi.org/10.5703/1288284315373

[21] Moser, V., Barišić, I., Rajle, D., \& Dimter, S. (2016, January). Comparison of different survey methods data accuracy for road design and construction. Proceedings of the International Conference on Road and Rail Infrastructure CETRA.

[22] Vick, S., \& Brilakis, I. (2018). Road Design Layer Detection in Point Cloud Data for Construction Progress Monitoring. Journal of Computing in Civil Engineering, 32(5), 04018029. https://doi.org/10.1061/(asce)cp.1943-5487.0000772 